\title{
The Antifa Marketing Model: Examination, Application, and Implications for Future Research
}

\author{
Lucy L. Henke \\ University of Louisiana at Lafayette
}

This paper analyzes the online presence of antifa from a marketing perspective to identify its marketing communication and brand-building tactics for comparison to those of other radical groups. Positioning itself as victim within a well-established grievance ideology is central to the antifa brand narrative, which uses a "persecution appeal" to persuade individuals to pursue a higher purpose by taking action against monolithic and powerful oppressors, thus transforming themselves into intellectually fascinating and emotionally compelling protagonists. The antifa model is used as a framework for analysis of Choose Democracy, another activist site. Similarities between the groups suggest that the antifa marketing model can be useful for analyzing and countering online radicalization.

Keywords: antifa marketing, antifascist, grievance ideology, persecution appeal, online radicalization, antifa brand narratives, choose democracy

\section{INTRODUCTION}

Many alternative groups have employed online marketing communication tactics to reach potential targets in hopes of forming a critical mass of followers to pursue their cause. Some have been successful, as evidenced by sudden on-the-spot appearances at designated locations by swarms of people prepared to engage in flash mobs for birthday surprises or in marches for political protests. How individuals apply principles of marketing in the digital world to indoctrinate recruits is a question for serious consideration by marketers, as religious extremists, anarchists, and other radical groups have increasingly more successfully lured and assimilated others into belief systems for fueling hatred and violence. What are the online strategies of extremist groups that have successfully created communities for their "brand" through social media? What content strategies are successful in recruiting followers and maintaining relationships with online contacts? Are there patterns that can be identified, and once identified, can countermeasures be designed to reverse their impact? Given the vastness and the dynamic, daily-changing nature of the Internet, the task of employing marketing strategy to gain an understanding of online radicalization is daunting, yet marketers have an overwhelming opportunity to break new ground in virgin territory. The current paper focuses on only a small but fundamental piece of the puzzle in an attempt to identify marketing strategies of radical groups as indicated by their websites and to evaluate the potential utility of strategies that employ various countermeasures. To that end, this paper critically examines the marketing communication strategy of "antifa," applies it to the assessment of a second activist group, seeks commonalities, and evaluates directions for future research programs to better understand and perhaps counteract the phenomenon. 


\section{THE ANTIFA MODEL}

Because of its rise to mass-mediated prominence for its participation in violent rioting after the 2016 election of Donald Trump and again in Portland and other American cities in the summer of 2020, antifa (a reference to "anti-fascism") is used in this paper as a model against which to compare the structure, goals, and marketing tactics of other radical groups with a social media presence. Thanks to the in-depth reporting of investigative journalist Andy Ngo (2021), it can clearly be argued that while it may not be a "monolithic, hierarchical" organization, antifa is neither a "myth" nor nonexistent, as some policymakers have claimed (Steinbuch 2021). Although it is steeped in secrecy, antifa is "very real" and may best be described as a collection of affinity groups that embrace the same political ideology (Bray 2020).

\section{Brand Awareness: Mission, Vision, and Goals}

What, then, is the mission of antifa? Many lofty goals are espoused by antifa groups, including liberty, justice, dignity, and equality, although prescribed methods for achieving them are unorthodox. One antifa group, the Revolutionary Abolitionist Movement ("RAM"), in its "10 Points of Action" literature, charts the routes to these goals by equating dignity with elimination of prisons, justice with a meting out by the oppressed, equality with the elimination of government, and liberation with the death of America (Anarchists Worldwide 2020). The proclaimed mission of antifa may appeal to a broad audience (after all, who can argue with the desire to defeat fascism and to achieve justice, dignity, equality, and liberation of the human spirit?) until these hypothetical constructs are further examined and unambiguously operationalized.

The "wolf in sheep's clothing" approach serves to elevate the publicly-touted purpose of participation in this ideology while masking the real purpose, and the attempt to wrap the organization's true motives in the flag of lofty aspirations reverberates throughout the antifa rhetoric. In their analysis of ten million social media comments, Finkelstein et al. (2020) demonstrated the widespread and growing use of memes and coded language among anarcho-socialist extremist groups. Use of coded language allows extremists to hide in plain sight while sharing ideas and planning action (Bloom, Tiflati, and Horgan 2019). For example, social media messages calling for followers to meet at a certain time and place, possibly to "defend" that place, is "cyberswarming" that often results in "network-enabled mobs" (Finkelstein et al. 2020). Antifa has evidently given serious consideration to linguistics. Riots are "uprisings." Violence against opponents is "self-defense." When opponents are murdered, "security" has effectively "neutralized a threat." Cries for "solidarity" are calls to other antifa groups to repeat the same violent actions in their respective cities (Ngo 2021).

\section{Building a Brand Narrative}

Beyond puffery of motives, the providing of a compelling narrative, much like the development of a brand story, is a key marketing tactic used by antifa. Narratives that elicit emotional responses and encourage identification with sympathetic characters who attempt to vanquish powerful enemies have been shown to be effective radicalization tools (Braddock 2015). Negative emotions in particular, such as anger and anxiety, have been shown to drive the virality of online content (Berger and Milkman 2012). The antifa narrative seeks to justify antifa's mission by delineating its struggle against powerful enemies and is an attempt to further sweeten its appeal, effectively putting into practice the "Principle of Antagonism" taught by renowned story design expert Robert McKee, namely: "A protagonist and his story can only be as intellectually fascinating and emotionally compelling as the forces of antagonism make them" (McKee 1997). Vanquishing a weak and feckless enemy is nothing to brag about, but a worthy and capable enemy can make one's quest that much more valiant, one's victories that much sweeter.

For its enemy list, antifa has rounded up as vile a collection of entities as possible: homophobes, racists, Nazis, white supremacists, and other despicable groups. Their websites feature literature steeped in intellectually seductive explications of the history of oppression suffered at the hands of the powerful European dictatorships of Hitler, Mussolini, and Franco, and trace the struggle from there to the current battle against more contemporary oppressors, the "amerikan [sic] settlers... who perceive amerika [sic] as 
having been betrayed and dirtied by immigrants, 'minorities,' queers, feminists, and a neoliberal capitalism" (Indigenous Action Media 2021). Some antifa sites draw a direct link from Hitler to President Trump, floating the rumor that Trump sleeps "with a volume of Hitler's speeches next to his bed" (Indigenous Action Media 2021). Having thus positioned itself against powerful, unrelenting, larger-than-life antagonists, antifa is poised to lay claim to title of intellectually fascinating and emotionally compelling protagonist.

\section{Grievance Ideology and Persecution Appeal}

Central to the antifa brand narrative is the antifa plight in the role of the victim, around which an entire grievance ideology has emerged. Hafez and Mullins (2015) have identified personal and collective grievances as essential pieces of the "radicalization puzzle," and a strong and repeatedly reinforced sense of victimization permeates the antifa ideology. Antifa literature employs what might best be termed a "persecution appeal," by which potential recruits are instructed in the myriad ways in which they have been victimized and their lives made miserable by oppressors, after which any of a number of remedies may be specified. (How do they wrong thee? Let me help you count the ways.) Rose City Antifa, the Portland, Oregon, affinity group, requires potential members to undergo a six-month training period during which the initiates study literature chosen to highlight the multitude of ways in which they have been oppressed, whether on the basis of race, or gender, or class, or sexual preference, or some combination thereof. Recruits spend one section of the training seeking answers to questions such as, "What is white skin privilege?" and another asking, "Why and how are you a feminist?" The curriculum is intended to arm the potential members with a working knowledge of the importance of militant antifascism, the structure of white supremacy, why and how to fight patriarchal oppression, and the ways in which intersectionality of oppression translates into real world violence (Ngo 2021). By the end of the course, students should have no shortage of convictions about the ways they have been victimized, regardless of their inventory of such beliefs at the beginning of the indoctrination.

\section{Calls to Action}

Similar to fear appeal (Janis and Feshbach 1953) or other successful advertising appeals, a persecution appeal that elucidates the ways in which the target audience has been victimized may arouse sufficient anxiety and emotional tension to induce action, in this case to defy the persecutor and prevent or reduce the victimization. Given this outcome, antifa stands ready to provide specific guidance for taking action. An important component of any effective marketing communication plan, a specific call to action is a prominent ingredient of antifa online communication as well as personal training.

The Rose City Antifa course modules, for example, require trainee instruction in enemy infiltration techniques, stealth tactics, ongoing martial arts practice, and "black bloc," the use of black clothing, ski masks, scarves, helmets, and other identify-concealing items. Participants are advised to create social media "sock puppets" to covertly observe enemy websites, to use Tor, Signal, Keypass, and other encrypted means of communication, and to develop their own strategic plans with instructor guidance (Ngo 2021).

Individual members also communicate with each other on social media sites such as Twitter and Facebook to transmit calls to action. Ngo (2021) cites instances of tweets that include a hashtag, the word "defend," and the name of a location (such as "\#DefendPDX" in which PDX, the designation for the Portland airport, is used to signify the city of Portland), that are calls for online members to mobilize to confront a target in real time on the streets of a real location.

\section{Brand Community}

Antifa's commitment to secrecy and self-concealment, the primary function of which may be to prevent the identification and arrest of members who engage in illegal activity, may also serve additional and significant functions from a marketing perspective. The shared secrecy may further strengthen the social and emotional bonds between group members (Rodriguez and Ryave 1992), and the requisite "black bloc" clothing characteristic of the antifa "brand community" are meaningful artifacts that may silently signal 
shared values and attitudes for instant solidarity (Muniz and O'Guinn 2001). The characteristic fist salute and the antifa logo additionally signal membership in antifa.

\section{Rational and Emotional Appeals to Gain Broad-Based Support}

Facilitating the maintenance of a broad base of support, antifa communicates with its membership and candidates for membership through both the central and the peripheral routes to persuasion (Petty and Cacciopo 1986). For audience members who require a rational, logical approach to arrive at adoption decisions, the antifa sites offer "left brain"-type literature tracing the intricate details of the history and purpose of the antifa ideology. Alongside these information-based arguments aimed perhaps at a more mature, more educated, or more discerning audience, comic book-style graphic nonfiction conveying similar information in different fashion often can be found on websites for antifa affinity groups (Indigenous Action Media 2017). The use of graphic nonfiction or animation as a "right brain" tool to transmit ideology is not unique to antifa, as other extremist groups have used cartoons in social media in attempts to recruit and radicalize young people (Thompson 2011). Including both types of information allows antifa websites to function as a sort of self-serve indoctrination tool, and potentially broadens the base of support for the organization.

\section{The Antifa Marketing Model}

In sum, several marketing techniques are used by antifa in communicating with and conveying its brand meaning to the online audience. First, the brand's "anti-America" stance is hidden behind calls to achieve a lofty set of goals that may appeal to a large audience and promote an initial awareness of the brand as virtuous. Second, an elaborate narrative communicates a brand story that justifies the pursuit of ambitions that equate "liberation" with the "death of America," and the extensive use of coded language may further promote a positive brand image to potential recruits as well as strengthen the bonds of the brand community members who can decode the messages. Third, a persecution appeal within a well-structured grievance ideology drives home the certainty that members of the organization are victims of powerful and relentless enemies. Fourth, calls to action delineate the specific ways that antifa members might pull together to vanquish the enemy and change the world in pursuit of a higher purpose. Finally, antifa provides both rational and emotional appeals and multiple types of content to satisfy varying levels of need for cognitive elaboration among its online audience members.

\section{CHOOSE DEMOCRACY}

Though one may think that a website called "Choose Democracy" may be an educational site listing the civic duties of individuals in a democracy, or describing the contributions one might make to strengthen one's democracy, or examining the U.S. Constitution and Declaration of Independence, the "Choose Democracy" website (https://choosedemocracy.us) was implemented several months prior to the 2016 Presidential election in anticipation of "an undemocratic power grab" in the event that President Trump would "try to steal the election." Choose Democracy is listed by the Federal Election Commission as an "unauthorized Super PAC" located in Washington, D.C. (https://www.fec.gov 2021). Influence Watch identifies it as a left-wing organization founded by two executives from 350.org, a "far-left environmental advocacy group" (https://www.influencewatch.org 2021). Unlike antifa, "Choose Democracy" overtly presents itself as a single organization with a specific mission. Nevertheless, the site displays many of the marketing tactics of the antifa affinity websites.

\section{Brand Awareness: Mission, Vision, and Goals}

The innocuous title of the website belies its activist nature. The first appearance of the Choose Democracy website on the Internet archive occurred August 27, 2020. At that time, the site contained a simple paragraph to explain its mission to thwart an impending coup, with separate links offering readers the opportunity to take a pledge, learn more, donate, or make contact. The hashtag "\#Choose Democracy" appeared in the top left corner of the main page. 
Like the antifa affinity groups, the organization's prose segues from the lure of lofty aspirations to statement of their true motives, from the large print heading of "Choose Democracy" to its smaller-print, bottom-line aim to recruit and organize people to take to the streets in mass protest should Donald Trump attempt to stage a coup in November. Specifically, the site states: "Democracy is fragile. We have reason to worry that this fall we may see an undemocratic power grab - a coup. We also know that the people can defend our democracy. Mass protests have stopped coups in other places, and we may have to do the same in this country. That's why we are committing now to choose democracy: by voting, making sure all the votes are counted, and preparing to take the streets in the case of a coup."

The four-part pledge that readers are urged to take includes the promise to vote, to refuse to accept election results until all votes are counted, to take to the streets if a coup is attempted, and to shut down the country if necessary. The actions required of recruits, as evidenced by the pledge, escalate from innocent civic duties (voting) to more drastic, undefined events (national shutdown). By the end of October, nearly 36,000 people had signed the pledge (Influence Watch 2020).

\section{Building a Brand Narrative}

Choose Democracy positions itself against Donald Trump based on the certainty that he will lose the Presidential election and refuse to accept the loss. As the website evolved, so did the brand image and product position. In September, the organization inserted "nonviolent" into the language before the phrase "mass protests" and included a section "About Us" to indicate the short-term nature of the platform, Nevertheless, the website continued to stress the urgency of the mission and the nefarious motives of the enemy, perhaps increasing the anxiety that would facilitate the growth of the follower group (Berger and Milkman 20120). By October 31, the site had added the "Coup-O-Meter," a speedometer-style graphic with four different-colored stages that range from "Democracy" (green) to "Preparing for a Coup" (yellow) to "Attempted Coup" (orange) to "Coup" (red), with the needle pointing to "Preparing for a Coup" but the dire possibilities looming just beyond. Anxious readers can visit the site on a regular basis to keep tabs on the status of the coup.

The grievance ideology and persecution appeal present in the antifa story are woven throughout the Choose Democracy narrative. To reinforce the importance of its work and strengthen its image as the emotionally compelling protagonist, Choose Democracy reminds readers that they are up against a powerful enemy, referencing whole countries "whose people experienced coups backed by the United States," including Iran, Guatemala, Congo, Brazil, Bolivia, and Chile. Like the brand narrative of antifa, Choose Democracy indicates that its enemy has a long and sordid international history. Like antifa, Choose Democracy encourages recruits to identify with the previously oppressed, calling it a lesson in empathy and reminding them that "Together we choose democracy." Like antifa, Choose Democracy narrative includes trigger words with the potential to increase anger and anxiety.

\section{Rational and Emotional Appeals to Gain Broad-Based Support}

Choose Democracy offers information that covers the spectrum from right brain to left brain, from emotional to rational. The site eventually came to include three internal links and twenty external links to anti-coup resources and stories about the organization. Like antifa, Choose Democracy offers various modes of acquiring information, to satisfy multiple needs and potentially gain broader support. The history of the countries that suffered coup attempts at the hands of the United States, for example, come complete with cartoons with captions, drawn in the style of the "Coup-O-Meter." Additional visually-based anticoup resources include two animated videos from the YouTube "Choose Democracy" channel, and a slide show explaining how to stop an election-related power grab, all reflecting the graphic style of the "CoupO-Meter," along with seven downloadable posters and an additional fifteen that are not downloadable.

For the times that online visitors are more interested in text-based resources, Choose Democracy provides external links to seven articles and three books, as well as two internal links to extensions of the text for more detail of the Choose Democracy story. The story contains both explanatory text as well as cartoons and graphic novel-style graphics. 


\section{Calls to Action for a Higher Purpose}

Calls to action and affiliation with like-minded organizations are characteristic of both the Choose Democracy and the antifa strategies. In addition, Choose Democracy employed the "Coup-O-Meter" to increase the urgency for action. Days after the election, on November 5, the Coup-O-Meter had moved up to the line between the yellow ("Preparing for a Coup") and orange ("Attempted Coup") values, signaling the increasingly dire straits in which the country found itself.

One of the more prominent features of the Choose Democracy website is its multitude of articles, handbooks, slide shows, books, manuals, and other tools providing guidance on how to participate in the anti-coup action. Online members never suffered from a lack of help in deciding how to take action for the cause. Quick-read e-zine articles include "What's the game plan if Trump really does try to steal the Election? 7 tactics to stop a coup" (Hunter 2020b), and "10 things you need to know to stop a coup" (Hunter 2020a), along with five others. Three heftier reads include books such as "Civil Resistance against Coups: A Comparative and Historical Perspective" (Zunes 2017), and "The Anti-Coup" (Sharp and Jenkins 2013). Some of the links reach affiliated websites, such as the "waging nonviolence" site that houses several of the e-zine articles.

The actions to which website visitors are called by Choose Democracy require varying levels of effort, but the primary message is clear: actions, no matter how small, in which "regular people" like the followers of the site may engage can change the world, and the organizers of the site are there to help at every step of the way. Signing and submitting the pledge requires very little commitment. Calling or writing a letter to local elections officials to demand a fair process requires minimal commitment, particularly since Choose Democracy provides a script and an affiliate group called "Protect Our Elections" will help with sending the pre-written letter. Joining a local group (searchable by zip code) may require only checking a box. Organizing one's own local group requires a substantial level of engagement, but for those who are interested in pursuing the development of a local group, Choose Democracy provides a guide for creating a pressure campaign. "Hitting the streets on November 7 to defend democracy" to join "hundreds of groups" planning a day of nationwide marches uses a bandwagon approach to take the edge off in the event the task appears too daunting. Follow-up actions that can be taken post-coup, in the event that Trump "coups," include instructions for engaging in activities outside local boards of elections and organizing "youth strikes" in conjunction with a group called "We Count On Us."

Because Donald Trump did not attempt to remain in the White House, Choose Democracy claims that his coup attempt failed and that they were successful in their mission to stop or prevent the coup. The organization and its website closed on January 21, 2021, but they remain online as a resource for future anti-coup efforts "anywhere around the world." It will not be possible to know what was intended by the directive to "hit the streets...to defend democracy" and whether "defend" holds the same meaning for Choose Democracy as it does for antifa, because the Choose Democracy followers stood down.

Regardless of whether Choose Democracy was able to carry out the actions for which it had planned, it was by all accounts a great success on other fronts. Influence Watch (2020) reports that Choose Democracy held training sessions with thousands of attendees in advance of the election, and the Federal Election Commission reports that the organization raised over $\$ 151,000$ and spent only about $\$ 63,000$, resulting in a hefty surplus by the end of 2020 (Federal Election Commission 2020).

\section{IMPLICATIONS FOR FUTURE RESEARCH}

\section{Social Network Analysis of Principals}

For both antifa and Choose Democracy, the groups appear to be inextricably linked to several other affinity organizations with similar overarching goals in overlapping fashion. Individual founders of one site (for example, 350.org, the "far-left environmental advocacy group") may found a politically-friendly site with, ostensibly, a completely different mission (for example, Choose Democracy, dedicated to stopping the theft of the presidency). For both antifa and Choose Democracy, the literature recommended on one site will often have backlinks from sites for other affinity groups. In fact, the interconnectedness that exists within the Choose Democracy/350.org/wagingnonviolence.org community reflects the very architecture 
that exists among the antifa "affinity groups." Social network analysis of the connections of online radical sites can potentially help to map the terrain, identify influential network members and "hubs" with the greatest number of social ties, and track their status as opinion leaders (Chen, van der Lans, and Phan 2017, Goldenberg et al. 2009). Social network analysis of the principals connected with each of the radical sites can conceivably yield rich data about the web of interconnections of the founders of radical sites which may appear to be abundant in number, but which may in fact consist only of a small number of prolific and interconnected activists with the luxury and financial resources to pursue their activities on a full-time basis.

\section{Cross-Platform Analysis}

The current paper focuses only on the main websites of the groups under study and does not consider the presence of the group or its members on Facebook, Twitter, Telegram, SnapChat, Instagram, or other social media sites, but research findings from analyses of brand communication strategies might effectively be applied to acquire an understanding of how online radical groups affect the perceptions and engagement levels of potential targets. How does the type and amount of consumer participation on an organization's social platform affect one's perceptions of the group? What impact can saturation across social media platforms have on reinforcing the organization's message and increasing bonds among its members? Research has examined whether "likes" on a social media platform, for example, may have a causal impact on customer offline behavior, or whether "liking" a brand can result in stronger personal ties with a brand (John et al. 2017, Mochon et al. 2017). A comprehensive research program would ideally investigate various groups' presence on other social media sites, potentially unlocking a rich data source for determining the ways in which strategies can be fine-tuned across social media platforms for greater effectiveness.

\section{Social Listening and Netnography}

An increasingly important method of capturing consumer attitudes and intentions is "social listening," tuning into conversations among consumers on Facebook, YouTube, Twitter, Instagram, and other social media sites to observe real exchanges in a natural environment, albeit online. Some researchers recommend going beyond simple observation to announce one's presence and interact with the other consumers (Kozinets 2002), but observation alone can yield tremendous insights into the worlds of online participants. Even with ultra-secretive antifa, for example, members may be identified and followed on the basis of their posting of "\#ACAB" or other symbols of significance to antifa on Twitter or other social media platforms. Netnography may yield more information about the interconnectedness of various radical groups through their individual memberships.

\section{DISCUSSION}

The two groups portrayed by the websites examined here have applied several fundamental marketing principles that distinguish them from other online organizations. Both state a mission, provide a brand narrative, apply persuasive appeals, and include specific calls to action. Specifically, both have a dual mission, one sweetened for public consumption, the other more genuine, and a clear message that the leaders of the groups as well as their intended target followers are oppressed parties who deserve to seek revenge against very powerful and ruthless enemies. Both steep themselves in historical legend to illustrate a grievance ideology and a saga of victimization. For both, a persecution appeal encourages bonding within the community, as misery loves miserable company (Schacter 1959). Both communicate loud and clear that leaders and their followers serve a higher purpose and are sure to change the world. Toward that end, both explain in abundant detail and offer to facilitate the ways in which followers may take action, however small, to vanquish the enemy and impact humanity. To collect a wider following, both use dual modes of communication, intellectualizing their mission through lengthy pieces of literature on the one hand, and complementing those messages with animations, cartoons drawings, and graphic nonfiction on the other, providing for veritable self-serve indoctrination. 
Marketers who wish to counter the online campaigns of successful radical extremists might infiltrate social media space to provide a counternarrative, might attempt to convince potential followers to pursue a different yet equally lofty purpose, and might encourage bonding on the basis of the ability to individually and collectively make positive change in the world. Unfortunately, several obstacles may need to be overcome for such a program to be successful. For example, while the radical group narrative may coax feelings of victimization from beneath the surface among their inductees, there may also be genuine tendencies toward a sense of injustice and victimization that would first need to be addressed. Other barriers may include the growing and well-documented divide between political factions in the United States and the resulting "spiral of silence" that encourages the creation of online echo chambers impermeable to opposing opinions (Dimock and Wike 2020, Glynn, Hayes, and Shanahan 1997, Noelle-Neumann 1977, Stoycheff 2016). While the task is daunting, marketing researchers are advantageously positioned to accept the challenge of understanding and counteracting the phenomenon of online radicalization.

\section{REFERENCES}

Anarchists Worldwide. (2020, February 1). So-Called USA: Revolutionary Abolitionist Movement 10 POINTS of ACTION. Retrieved from http://archive.vn/YyF2b and https://anarchistsworldwide.noblogs.org/post/2020/01/02/so-called-usa-revolutionary-abolitionistmovement-10-points-of-action/

Berger, J., \& Milkman, K. (2012). What makes online content viral? Journal of Marketing Research, 49(2), 192-205.

Braddock, K. (2015). The Utility of Narratives for Promoting Radicalization: The Case of the Animal Liberation Front. Dynamics of Asymmetric Conflict, 8(1), 38-59.

Bray, M. (2020, September 11). Five Myths About Antifa. Washington Post. Retrieved from http://washingtonpost.com/outlook/five-myths/five-myths-about-antifa/2020/09/11/527071 acf37b-11ea-bc45-e5d48ab44b9f_story.htm

Chen, X., van der Lans, R., \& Phan, T.Q. (2017). Uncovering the importance of relationship characteristics in social networks: Implications for seeding strategies. Journal of Marketing Research, 54(2), 187-201.

Choose Democracy website. (2020, August 27). Retrieved from https://web.archive.org/web/20200827200913/https://choosedemocracy.us/

Choose Democracy website. (2020, November 5). Retrieved from https://web.archive.org/web/20201105145430/http://choosedemocracy.us/

Choose Democracy website. (2020, October 31). Retrieved from https://web.archive.org/web/20201031234757/https://choosedemocracy.us/

Choose Democracy website. (2020, September 9). Retrieved from https://web.archive.org/web/20200909124140/https://choosedemocracy.us/

Dimock, M., \& Wike, R. (2020). America is exceptional in the nature of its political divide. Pew Research Center. Retrieved from https://www.pewresearch.org/fact-tank/2020/11/13/america-isexceptional-in-the-nature-of-its-political-divide

Federal Election Commission Choose Democracy. (2020, February 18). Retrieved from https://www.fec.gov/data/committee/C00756734/

Finkelstein, J., Goldenberg, A., Stevens, S., Paresky, P., Jussim, L., Farmer, J., \& Donohue, J.K. (2020, September 14). Network-Enabled Anarchy: How Militant Anarcho-Socialist Networks Use Social Media to Instigate Widespread Violence Against Political Opponents and Law Enforcement. Rutgers Network Contagion Research Institute.

Glynn, C.J., Hayes, A.F., \& Shanahan, J. (1997). Perceived Support for One's Opinions and Willingness to Speak Out: A Meta-Analysis of Survey Studies on the 'Spiral of Silence'. Public Opinion Quarterly, 61, 452-463.

Goldenberg, J., Han, S., Lehmann, D.R., \& Hong, J.W. (2009). The role of hubs in the adoption process. Journal of Marketing, 73(2), 1-13. 
Hafez, M., \& Mullins, C. (2015). The Radicalization Puzzle: A Theoretical Synthesis of Empirical Approaches to Homegrown Extremism. Studies in Conflict \& Terrorism, 38, 958-975.

Hunter, D. (2020a, September 18). 10 things you need to know to stop a coup. Retrieved from https://wagingnonviolence.org/2020/09/10-things-you-need-to-know-to-stop-a-coup

Hunter, D. (2020b, October 21). What's the game plan if Trump really does try to steal the election? 7 tactics to stop a coup. Retrieved from https://wagingnonviolence.org/2020/10/7-tactics-to-stop-acoup

Indigenous Action Media. (2017). Fascism \& Anti-Fascism: A Decolonial Perspective. Retrieved April 11, 2021, from https://indigenousaction.org/wp-content/uploads/Fascism-Anti-Fascism-ADecolonial-Perspective-1.pdf

Influence Watch. (2020). Retrieved March 3, 2020, from https://www.influencewatch.org/nonprofit/choose-democracy/

Janis, I., \& Feshbach, S. (1953). Effects of fear arousal. Journal of Abnormal and Social Psychology, 48, $78-92$.

Kozinets, R. (2002, February). The Field Behind the Screen: Using Netnography for Marketing Research in Online Communities. Journal of Marketing Research, 39, 61-72.

McKee, R. (1997). Story: Substance, Structure, Style, and the Principles of Screenwriting. New York: Harper Collins.

Muniz, A.M., Jr., \& O’Guinn, T.C. (2001, March). Brand Community. Journal of Consumer Research, $27,412-432$.

Ngo, A. (2021). Unmasked: Inside Antifa's Radical Plan to Destroy Democracy. New York: Center Street.

Noelle-Neumann, E. (1977). Turbulence in the Climate of Opinion: Methodological Applications of the Spiral of Silence Theory. Public Opinion Quarterly, 41, 143-158.

Petty, R.E., \& Cacciopo, J.T. (1986). The Elaboration Likelihood Model of Persuasion. Advances in Experimental Social Psychology, 19, 1123-205.

Sharp, G., \& Jenkins, B. (2013). The Anti-Coup. Boston: The Albert Einstein Institution.

Steinbuch, Y. (2020, July 27). Rep. Jerry Nadler Calls Violence from Antifa in Portland a 'Myth'. New York Post. Retrieved from https://nypost.com/2020/07/27/jerry-nadler-calls-violence-from-antifain-portland-a-myth

Stoycheff, E. (2016). Under Surveillance: Examining Facebook's Spiral of Silence Effects in the Wake of NSA Internet Monitoring. Journalism \& Mass Communication Quarterly, pp. 1-16.

Thompson, R.L. (2011, Winter). Radicalization and the Use of Social Media. Perspectives on Radicalization and Involvement in Terrorism, 4(4), 167-190.

Zunes, S. (2017). Civil Resistance Against Coups: A Comparative and Historical Perspective. ICNC Monograph Series, Washington, D.C.: International Center on Nonviolent Conflict. 